\title{
PERDA DE MASSA FRESCA DOS FRUTOS EM PROGÊNIES DE MARACUJAZEIRO-AMARELO ${ }^{1}$
}

\author{
CARLOS EDUARDO MAGALHÃES DOS SANTOS ${ }^{2}$, HELOÍSA LINHALES ${ }^{3}$, LUÍSA LORENTZ MAGALHÃES PISSIONI ${ }^{4}$, \\ DANIELLA DE CÁSSIA SILVACARRARO ${ }^{4}$, JOSÉ OSMAR DA COSTAE SILVA ${ }^{3}$, CLAUDIO HORST BRUCKNER ${ }^{5}$
}

RESUMO-O maracujá-amarelo (Passiflora edulis Sims f. flavicarpa Deg.) perde valor durante sua comercialização devido a alterações na aparência dos frutos. Objetivou-se, neste estudo, avaliar a perda de massa da matéria fresca dos frutos em progênies de irmãoscompletos de maracujazeiro-amarelo. Os frutos foram colhidos na área experimental e avaliados no Laboratório de Análise de Frutas pertencentes ao Departamento de Fitotecnia da Universidade Federal de Viçosa (UFV). Determinou-se a perda de matéria fresca durante os onze primeiros dias após a colheita, de cinco progênies de irmãos-completos provenientes do programa de melhoramento genético do maracujazeiro da UFV. O experimento foi instalado em esquema de parcelas subdivididas, tendo nas parcelas as progênies, e nas subparcelas, os períodos de avaliações em dias. A perda de massa da matéria fresca foi determinada em balança semi-analítica, sendo a diferença de massa acumulada durante a evolução do experimento, e o resultado de perda de massa da matéria fresca em relação à massa inicial do fruto, expressos em percentagem. Foi utilizado o delineamento em blocos casualizados, com quatro repetições e quatro frutos por unidade experimental. As progênies avaliadas apresentaram comportamento pós-colheita diferenciado, e os resultados indicam a necessidade de incluir a resistência à perda de massa da matéria fresca dos frutos entre os objetivos do melhoramento.

Termos para indexação: Passiflora edulis f. flavicarpa, progênies, pós-colheita.

\section{FRESH FRUIT WEIGHT LOSS OF PROGENIES OF YELLOW PASSION FRUIT}

\begin{abstract}
The yellow passion fruit (Passiflora edulis Sims f. flavicarpa Deg.) lost value during its commercialization because of some alterations in its fruit appearance. The aim of this study was to evaluate the fresh fruit weight loss of progenies from yellow passion fruit. The fruits were harvest in the experimental area and evaluated in the Laboratory of Analysis of Fruits, in the Plant Science Department, University Federal of Viçosa (MG - Brazil). It was determined the mass loss of fresh matter during the eleven first days after the harvest, of five germanic siblings progenies from the UFV breeding passion fruit program. The experiment was in a subdivided plot design, considering the progenies as a plot, and the evaluations periods in days as subplot. The mass loss of fresh matter was evaluated in semi-analytical scale, being the difference of accumulated mass during the experiment evolution and the result of loss mass of fresh matter in relation to the fruit initial mass, expressed in percentage. The experiment was designed in a completely randomized blocks, with four replications, where each plot constituted of four fruits. The progenies evaluated presented post harvest behavior differentiated; the results indicate the need to include the resistance to the mass loss of the fresh matter of the fruits among the objectives of the improvement.
\end{abstract}

Index terms: Passiflora edulis f. flavicarpa, progenies, post harvest.

\section{INTRODUÇÃO}

O maracujazeiro-amarelo (Passiflora edulis Sims f. flavicarpa Deg.) é nativo da América do Sul e amplamente cultivado em países tropicais e subtropicais, sendo o Brasil um dos principais produtores dessa fruta (Lima, 2002). A espécie apresenta frutos com respiração climatérica (Pocasangre Enamorado et al., 1995), o que lhes permite completar sua maturação fora da planta (Salunke \& Desai, 1984). O fruto atinge seu ponto de colheita em 50-60 dias após a antese, ou seja, 20 a
30 dias antes de se desprender da planta-mãe. Nesse ponto, apresenta máximo peso (50-130 g), máximo rendimento em suco (até $36 \%$ ) e maior conteúdo de sólidos solúveis ( 13 a $18^{\circ}$ Brix), podendo ser caracterizado pela coloração verde-amarelada, mas ainda preso à planta-mãe (Ruggiero et al., 1996).

Quando destinado ao mercado 'in natura', o critério mais utilizado para avaliar a qualidade dos frutos é a aparência externa e, no caso do maracujá, um dos problemas durante a comercialização é a ocorrência de murcha e enrugamento, conferindo má aparência e perda de qualidade (Tavares et al., 2003). Essa perda de qualidade e, conseqüentemente, de valor

'(Trabalho 011/07). Recebido em: 03-01-2007. Aceito para publicação em: 14-11-2007.Trabalho executado com apoio financeiro da CAPES, CNPq e FAPEMIG.

${ }^{2}$ Eng. Agr. Dsc., Bolsista de Pós-Doutorado/FAPEMIG - UFV. CEP. 36570-000 - e-mail: eduardomagsantos@yahoo.com.br

${ }^{3}$ Eng. Agr. Mestrando em Fitotecnia - UFV - Bolsista CNPq. CEP. 36570 - 000 - e-mail: heloisalin@yahoo.com.br; joksilva7@yahoo.com.br.

${ }^{4}$ Acadêmicos do curso de agronomia - UFV. Bolsista Pibic/Caixa. CEP: 36570 - 000 - e-mail: lulorentz@hotmail.com; carrarodaniagro@hotmail.com.

${ }^{5}$ Eng. Agr. DS., Professor Titular do Departamento de Fitotecnia, UFV. Viçosa - MG. CEP 36570-000. Bolsista CNPq. e-mail: bruckner@ufv.br. 
comercial, ocorre em razão da intensa atividade respiratória e da elevada perda de água (Castro, 1994; Scheer, 1994).

Para o mercado de fruta fresca, recomenda-se a colheita na planta, quando os frutos apresentam, pelo menos, $30 \%$ de coloração amarela, evitando-se sua queda ao solo. A conservação pós-colheita do fruto tem gerado grande preocupação, visto que ele é perecível e dura, em condições normais, três a sete dias à temperatura ambiente (Arjona et al., 1992). Após esse período, os frutos murcham rapidamente, a polpa começa a fermentar e inicia-se o ataque de fungos. A boa conservação dos frutos por período mais longo é de fundamental importância para a comercialização eficiente do produto destinado ao mercado de frutas frescas e traz benefícios para toda a cadeia de produção (Lima, 2002).

Nos programas de melhoramento do maracujazeiro, os principais aspectos estudados são: o aumento da produção, a resistência a pragas e doenças e a melhoria da qualidade dos frutos (Bruckner et al., 2002). Esta última está associada, entre outros aspectos, à maior conservação natural dos frutos em póscolheita, e pode ser conseguida por meio da produção de frutos com baixa taxa de murchamento, associados a uma melhor coloração.

Não são encontradas referências na literatura sobre o efeito genético na conservação do maracujá. Assim, objetivouse, neste trabalho, determinar a perda de massa da matéria fresca dos frutos de cinco progênies de maracujazeiro-amarelo e se existe influência genética na perda de massa fresca dos frutos.

\section{MATERIAL E MÉTODOS}

O trabalho foi desenvolvido no Departamento de Fitotecnia da Universidade Federal de Viçosa, analisando-se frutos de cinco progênies de irmãos-completos de maracujazeiroamarelo provenientes do programa de melhoramento genético da Universidade Federal de Viçosa-MG.

Os frutos foram colhidos quando apresentavam entre 25 e 50\% da coloração da casca amarela e ainda aderidos à planta-mãe. Após, procedeu-se à seleção dos frutos, descartando-se aqueles que apresentaram algum dano mecânico, defeitos, sintomas de doenças e desuniformidade em comprimento longitudinal e diâmetro equatorial.

$\mathrm{O}$ experimento foi instalado em esquema de parcelas subdivididas, tendo nas parcelas as progênies $(1 ; 2 ; 3 ; 4$ e 5$)$ e nas subparcelas os períodos de avaliações $(1 ; 2 ; 3 ; 4 ; 5 ; 6 ; 7 ; 8$; 9; 10 e 11 dias após o início do experimento). O delineamento utilizado foi em blocos casualizados, com 4 repetições e quatro frutos por unidade experimental.

Após a seleção, os frutos foram mantidos em temperatura ambiente, avaliando-se, desde o dia da colheita até o décimo primeiro dia após a colheita, a perda de massa da matéria fresca. A perda de massa da matéria fresca foi determinada em balança de precisão marca Núcleo (Modelo NC $5000 \mathrm{NW}$ ), com precisão de $0,01 \mathrm{~g}$, sendo a perda de massa de matéria fresca, em relação à massa inicial do fruto, expressa em percentagem.

Os dados foram submetidos à análise de variância e de regressão, sendo analisados pelo programa GENES (Cruz, 2001).

\section{RESULTADOS E DISCUSSÃO}

De acordo com os resultados obtidos, observou-se diferença significativa quanto à interação progênie $\mathrm{x}$ período de avaliação (Tabela 1), indicando a existência de comportamento diferenciado entre as progênies. A perda de massa da matéria fresca foi linear em todas as progênies, mas os coeficientes angulares foram diferentes entre elas. A progênie 5 apresentou menor perda de massa de matéria fresca no final do período de avaliação, em relação às demais, as quais apresentaram comportamento semelhante entre si (Figura 1). Assumindo como aceitável uma perda de $5 \%$ da massa da matéria fresca, esta seria alcançada em 5 dias, nos frutos da progênie 3, enquanto na progênie 5 a mesma perda foi alcançada aos sete dias, o que constitui uma diferença considerável por tratar-se de fruto perecível.

A perda de massa de matéria fresca que ocorre no armazenamento de frutos de maracujazeiro é considerada fator limitante para sua conservação. Por causa da rápida perda de massa ao longo do período de armazenamento, os frutos apresentam enrugamento da casca devido ao processo de senescência, mesmo com a polpa estando em boas condições para consumo e sendo, por este motivo, comercialmente desvalorizados. Para evitar problemas de aceitação no mercado, os frutos de maracujazeiro-amarelo devem ser comercializados logo após a colheita, evitando-se, assim, grandes prejuízos para os produtores (Campos et al., 2005).

A perda de massa da matéria fresca do maracujá tem sido minimizada com armazenamento em temperaturas baixas (Arjona et al., 1992), revestimentos com ceras e filmes plásticos (Gama et al., 1991; Mota et al., 2003) e utilização de atmosfera modificada (Resende et al., 2001). Esses processos permitiram retardar a perda de $5 \%$ em torno de 1 a 2 dias. Segundo Silva (1983), no maracujáamarelo, essas perdas chegam a $10 \%$ da massa de matéria fresca do fruto. Campos et al. (2005), empregando tratamento térmico na conservação pós-colheita do maracujá-amarelo, obtiveram menor perda de massa no tratamento sem utilização de agentes térmicos, verificando, no quinto dia de avaliação, perda em torno de 12\%. Já Gama et al. (1991) observaram perdas de 9,34\% de massa da matéria fresca em frutos de maracujazeiro-amarelo após 14 dias de armazenamento à temperatura de $6^{\circ} \mathrm{C}$. Estes mesmos autores, associando embalagem de polietileno ao armazenamento a $6^{\circ} \mathrm{C}$, observaram que a perda de massa foi ao redor de $1 \%$ durante 42 dias de armazenamento.

No presente trabalho, a possibilidade de retardar a perda de $5 \%$ da massa de matéria fresca em dois dias ( $40 \%$ de aumento do tempo) pode ser considerada significativa, pois indica a possibilidade de obtenção de cultivares com maior capacidade de conservação, sem custos adicionais, além do custo da semente, viabilizando, inclusive, melhor conservação de frutas produzidas por pequenos agricultores. Atualmente, os objetivos do melhoramento são alta produtividade, alto vigor, resistência ou tolerância a pragas e doenças, adaptação ampla, frutos grandes, alto teor de suco, coloração amarelo-dourada do suco, alto teor de sólidos solúveis e de acidez e resistência a transporte 
e armazenamento (Meletti et al., 2000; Bruckner et al., 2002; Negreiros et al., 2004). Percebe-se, pois, que os resultados deste trabalho indicam a necessidade de se incluir a resistência à perda de massa da matéria fresca dos frutos entre os objetivos do melhoramento.

TABELA 1 - Análise de variância da perda de massa da matéria fresca de 5 progênies de maracujazeiro-amarelo ao longo do período de armazenamento. Universidade Federal de Viçosa. Viçosa-MG 2006

\begin{tabular}{|c|c|c|}
\hline & & Quadrado Médio \\
\hline F.V. & G.L. & Perda de Massa \\
\hline$\overline{\text { Blocos }}$ & 3 & 1,2323 \\
\hline Genótipos (G) & 4 & $94,1120 * *$ \\
\hline Períodos de Avaliação (P) & 10 & $104,7013 * *$ \\
\hline$G \times P$ & 40 & $11,9019 * *$ \\
\hline Resíduo & 150 & 0,3255 \\
\hline CV(\%) Parcela & & 18,63 \\
\hline CV(\%) Subparcela & & 29,35 \\
\hline
\end{tabular}

** Significativo a $1 \%$ de probabilidade, pelo teste $\mathrm{F}$.

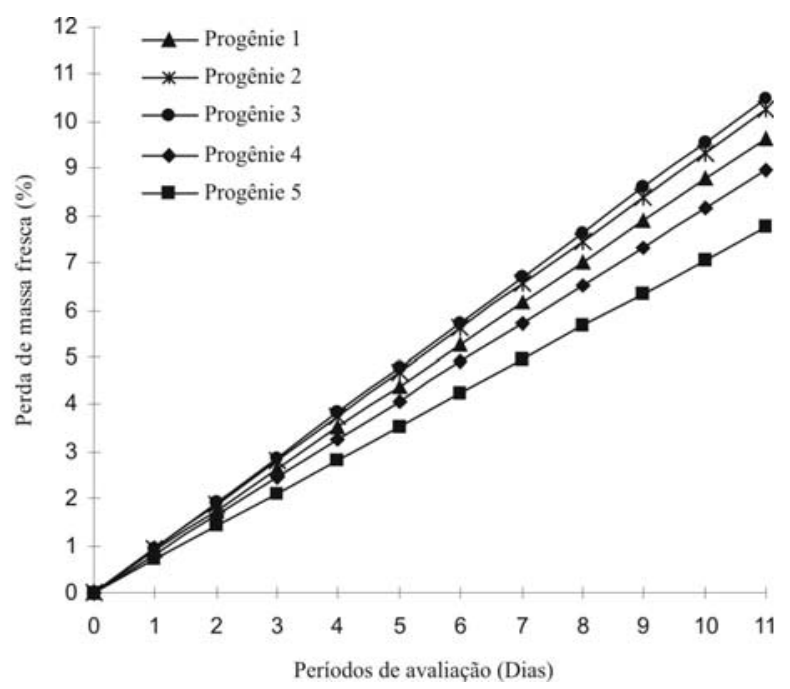

FIGURA 1 - Perda de massa da matéria fresca de frutos provenientes de 5 progênies de maracujazeiroamarelo avaliadas ao longo do período de armazenamento. Universidade Federal de Viçosa Viçosa-MG, 2006.

\section{CONCLUSÕES}

1-As progênies avaliadas apresentam comportamento pós-colheita diferenciado, em razão da variabilidade genética.

2-Os resultados indicam a pertinência de que a resistência à perda de massa fresca seja incluída nos objetivos do melhoramento.

\section{REFERÊNCIAS}

ARJONA, H. E.; MATTA, F. B.; GARNER JÚNIOR, J. O. Temperature and storage time affect quality of yellow passion fruit. HortScience, Alexandria, v. 27, n. 7, p. 809-810, 1992.

BRUCKNER, C. H.; MELETTI, L. M. M.; OTONI, W. C.; ZERBINI JÚNIOR, F. M. Maracujazeiro. In: BRUCKNER, C. H. (Ed.) Melhoramento de fruteiras tropicais. Viçosa: Editora UFV, 2002. p. 373-409.

CAMPOS, A. J. de; MANOEL, L.; DAMATTO JÚNIOR, E. R.; VIEITES, R. L.; LEONEL, S.; EVANGELISTA, R. M. Tratamento hidrotérmico na manutenção da qualidade pós-colheita de maracujá-amarelo. Revista Brasileira de Fruticultura, Jaboticabal, v. 27, n. 3, p. 383-385, dec. 2005.

CASTRO, J. V. Matéria-prima. In: TEIXEIRA, C. G., CASTRO, J. V.; TOCCHINI, R. P.; NISIDA, A. L. A. C.; HASHIZUME, T.; MEDINA, J. C.; TURATTI, J. M.; LEITE, R. S. S. F.; BLISKA, F. M. M; GARCIA, A. E. B. Maracujá: cultura, matéria-prima, processamento e aspectos econômicos. 2.ed. Campinas: ITAL, 1994. p.143-160. (Série Frutas Tropicais, 9).

CRUZ, C. D. Programa GENES - versão windows (2004.2.1). Viçosa: Editora UFV, 2001.642p.

GAMA, F. S. N.; MANICA, I.; KIST, H. G. K.; ACCORSI, M. R. Aditivos e embalagens de polietileno na conservação do maracujá-amarelo armazenado em condições de refrigeração. Pesquisa Agropecuária Brasileira, Brasília, v. 26, n. 3, p. 305310, mar. 1991.

LIMA, A. de A. Maracujá produção: aspectos técnicos. Cruz das Almas: Embrapa Mandioca e Fruticultura, Cruz das Almas. Brasília: Embrapa Informação Tecnológica, 2002.p. 103. (Frutas do Brasil; 15).

MELETTI, L. M. M.; AZEVEDO FILHO, J. A.; BENTO, M. M. 'IAC 275' - Primeira cultivar de maracujazeiro-amarelo (Passiflora edulis f. flavicarpa) para a agroindústria de sucos. In: SIMPÓSIO BRASILEIRO DE MELHORAMENTO DE FRUTEIRAS, 2., 2000, Viçosa. Anais... Viçosa: Editora UFV, 2000. p. 166.

MOTA, W. F.; SALOMÃO, L. C. C.; CECON, P. R.; FINGER, F. L. Waxes and plastic film in relation to the shelf life of yellow passion 
fruit. Scientia Agricola, Piracicaba, v. 60, n. 1, p. 51-57, Jan./Mar. 2003.

NEGREIROS, J. R. da S.; BRUCKNER, C. H.; CRUZ, C. D.; SIQUEIRA, D. L. de; PIMENTEL, L. D. Seleção de progênies de maracujazeiro-amarelo vigorosas e resistentes à verrugose (Cladosporium cladosporioides). Revista Brasileira de Fruticultura, Jaboticabal, v. 26, n. 2, p. 272-275, 2004.

POCASANGRE ENAMORADO, H. E.; FINGER, F. L.; BARROS, R. S.; PUSCHMANN, R. Development and ripening of yellow passion fruit. Journal of Horticultural Science, Ashford, v. 70, p. 573-576, 1995 .

RESENDE, J. M.; VILAS BOAS, E. V. de B.; CHITARRA, M. I. F. Uso de atmosfera modificada na conservação pós-colheita do maracujá amarelo. Ciência Agrotecnologia, Lavras, v. 25, n. 1, p.159-168, 2001.
RUGGIERO, C.; SÃO JOSÉ,A. R.; VOLPE, C. A.; OLIVEIRA, J.C. de; DURIGAN, J. F.; BAUMGARTNER, J. G.; SILVA, J. R.; NAKAMURA, K.; FERREIRA, M. E.; KAVATI, R.; PEREIRA, V. de P. Maracujá para exportação: aspectos técnicos da produção. Brasília: EMBRAPA, SPI, 1996. 64p. (Série Publicações Técnicas FRUPEX, 19).

SALUNKE, D. K.; DESAY, B. B. Postharvest biotechnology of fruits. Boca Raton: CRC Press, 1984. v.2, 147 p.

SCHEER, A. Reducing the water loss of horticultural and arable products during long term storage. Acta Horticulturae, Wageningen, n. 368, p. 511-522, 1994.

SILVA, J. B. da. Suco de maracujá. Informativo Semanal Cacex, Rio de Janeiro, n. 835, p.1-32, 1983.

TAVARES, J. T. de Q.; SILVA, C. L. da; CARVALHO, L. A. de; SILVA, M. A. da; SANTOS, C. M. G.; TEIXEIRA, L. de J.; SANTANA, R. da S. Aplicação pós-colheita de cloreto de cálcio em maracujá-amarelo. Magistra, Cruz das Almas, v. 15, n. 1, Jan./ Jun. 2003. 